ADDIN, Vol. 10, No. 1, Februari 2016

\title{
PANDANGAN HIZBUT TAHRIR TERHADAP RADIKALISME GERAKAN ISIS DALAM MENEGAKKAN DAULAH KHILAFAH
}

\author{
Arif Muzayin Shofwan \\ Universitas Muhammadiyah Malang, Jawa Timur, Indonesia \\ arifms78@yahoo.co.id
}

\section{Abstrak}

ISIS (Islamic State of Iraq and Syria) merupakan gerakan Islam radikal yang dideklarasikan oleh Abu Bakar al-Baghdad dan ingin menegakean daulah khilafah Islam di Iraq dan Syiria. Sementara itu, Hizbut Tabrir (HT) juga merupakan gerakan Islam radikal yang memiliki cita-cita menegakekan daulah khilafah Islam. Namun, ternyata kedua gerakan tersebut memiliki langkah atau cara yang berbeda dalam mewnjudkan cita-cita tersebut. Tulisan ini bertujuan menjelaskan pandangan Hizbut Tabrir terhadap cara gerakan ISIS dalam mewujudkan daulah khilafah Islam. Temuan dalam studi ini menjelaskan bahwa walau kedua gerakan radikal Islam Hiz̧but Tabrir dan ISIS mempunyai cita-cita yang sama dalam menegak.kan daulah kbilafah Islam, akan tetapi keduanya memiliki cara yang berbeda dalam mewnjudkan hal tersebut. Hiøbut Tabrir tidak sepakat dan babkan menolak keras terhadap penegakan daulah kbilafah Islam yang dilakukan ISIS dengan jalan kekerasan. Hizbut Tahrir memandang babwa penegakan daulah khilafah Islam yang dilakukan oleh gerakan ISIS tidak memenubi empat syarat yang ditawarkan gerakan Hizbut Tabrir. Dengan demikian, dalam pandangan Hizbut Tabrir, penegakan 
Arif Muzayin Shofwan

daulah khilafah gerakan ISIS tidak sesuai ajaran Rasulullah saw manakala mendirikan negara Islam.

Kata Kunci: Hizbut Tahrir, ISIS, Radikalisme, dan Daulah

Khilafah Islam.

\section{Abstract}

THE VIEWS OF HIZBUT TAHRIR TO ISIS RADICALISM IN ESTABLIS HING KHILAFAH: ISIS (Islamic State of Iraq and Syria) is a radical Islamic movement, which was declared by Abu Bakar al-Baghdadi and it wanted to enforce the Islamic caliphate in Iraq and Syria. Meanwbile, Hizbut-Tabrir (HT) is also a radical Islamic movement that has the ideals of the Islamic caliphate. However, the two movements have different ways of realizing these ideals. This article aims at explaining the views of the Hirbut Tabrir to the ways in realizing the movement of ISIS in actualizing the Islamic caliphate. The findings in this study were that both the radical Islamic movements of Hizbut Tabrir and ISIS have the same ideals in enforcing the Islamic caliphate, but they have different ways to achieve this goal. Hizbut-Tabrir did not agree and even refused against the enforcement of the Islamic caliphate carried by ISIS using the violence. Hizbut Tabrir considers that the enforcement of the Islamic caliphate conducted by ISIS does not meet the four conditions offered by the Hirbut Tabrir. Thus, in the view of the Hizbut Tabrir, the enforcement of ISIS caliphate is not according to the teachings of the Prophet when establishing an Islamic state.

Keywords: Hizbut Tahrir, ISIS, Radicalism, the Islamic Khilafah.

\section{A. Pendahuluan}

Fenomena radikalisme Islam diyakini oleh banyak pihak sebagai ciptaan abad ke-20 di dunia muslim, terutama Timur Tengah, sebagai krisis identitas yang berujung pada reaksi dan resistensi terhadap Barat yang menebarkan kolonialisasi di negara muslim. Terpecahnya dunia muslim ke dalam berbagai negara bangsa (nation-state) dan proyek modernisasi yang dicanangkan pemerintah baru berhaluan Barat mengakibatkan umat Islam merasakan mengikisnya ikatan agama dan moral yang sudah lama mereka pegangi. Hal ini menyebabkan munculnya gerakan- 
gerakan Islam radikal yang menyerukan kembali kepada ajaran Islam yang murni sebagai jalan keluar. Tidak sampai di situ, gerakan ini melakukan perlawanan terhadap rezim yang dianggap sekuler dan menyimpang dari agama. ${ }^{1}$

Indonesia yang biasa disebut "Nusantara" sejak awal kelahiran agama Islam dipandang memiliki watak moderat dan toleran. Pengislaman yang dilakukan para wali di negeri tersebut dilakukan melalui kontak dagang, perkawinan, akulturasi budaya, dan semacamnya. Islam disebarkan dengan kehalusan budi pekerti, sehingga dapat membaur dengan berbagai tradisi yang mapan sebelumnya. ${ }^{2}$ Namun, wajah Islam yang moderat dan toleran menjadi berubah manakala Orde Baru tumbang dan berganti era reformasi. Pada era reformasi inilah bibit-bibit gerakan Islam yang berhaluan radikal mulai tampak. Adapun beberapa kelompok Islam radikal yang mulai mendapatkan ruang pasca tumbangnya Orde Baru di antaranya: Hizbut Tahrir Indonesia (HTI) atau biasa disebut HT saja, Majelis Mujahidin Indonesia (MMI), Front Pembela Islam (FPI), Jama'ah Islamiyah (JI), Negara Islam Indonesia (NII), Laskar Jihad (LJ), dan semacamnya. ${ }^{3}$

Tidak mudah untuk membendung arus radikalisme Islam tersebut. Syamsul Arifin dalam buku yang berjudul "Studi Islam Kontemporer Arus Radikalisasi dan Multikulturalisme di Indonesia" menyatakan bahwa Islam radikal memilikiwatak keabadian. Dengan demikian, sangat sulit untuk menjawab apakah arus radikalisasi Islam tersebut bisa dibendung. ${ }^{4}$ Terbukti bahwa pada akhir-akhir ini banyak berita yang cukup menyita perhatian publik terutama tentang perihal sepak terjang gerakan radikal ISIS (Islamic State of Iraq and Syria) yang telah mendeklarasikan daulah khilafah Islam yang mereka yakini kebenarannya. Apalagi setelah muncul seruan

${ }^{1}$ Syamsul Rijal, "Radikalisme Islam Klasik dan Kontemporer: Membanding Khawarij dan Hizbut Tahrir", Al-Fiker, Vol. 14, No. 2, 2010, hlm. 215.

2 Mohammad Atho Mudzhar, Fatwa-fatwa Majelis Ulama Indonesia Jakarta: INIS, 1993), hlm. 8-9.

${ }^{3}$ Abu Rokhmad, "Pandangan Kiai tentang Deradikalisasi Paham Islam di Kota Semarang”, Jurnal Analisa, Vol. 21, No. 01, Juni 2014, hlm. 28.

${ }^{4}$ Syamsul Arifin, Studi Islam Kontemporer Arus Radikalisasi dan Multikulturalisme di Indonesia (Malang: Intrans Publishing, 2015), hlm. vii. 
(da'wah) ISIS dalam rekaman video di situs Youtube yang mengajak seluruh umat Islam untuk segera bergabung dengan ISIS. Pasca adanya seruan tersebut, maka pemberitaan tentang ISIS makin gencar di media cetak, elektronik dan online. Seminar, diskusi dan bincang-bincang kecil tentang ISIS muncul dimana- mana. ${ }^{5}$

Kemunculan gerakan Islam radikal ISIS yang telah medeklarasikan penegakan daulah khilafah Islam tersebut, ternyata mendapat kecaman dari kelompok Hizbut Tahrir (HT) yang juga merupakan gerakan radikal. Padahal kedua gerakan radikal (ISIS dan HT) tersebut memiliki cita-cita yang sama dalam menegakkan daulah khilafah Islam. Tentu saja, perbedaan kedua gerakan radikal tersebut sangat menarik untuk diteliti atau dikaji. Dalam studi ini, meneliti pandangan Hizbut Tahrir (HT) terhadap cara penegakan daulah khilafah Islam yang dilakukan gerakan radikal ISIS akan menjadi prioritas utama. Hal tersebut tentu tidak berlaku sebaliknya, mengingat bahwa banyaknya anggota kelompok radikal Hizbut Tahrir (HT) dalam konteks Indonesia, akan memudahkan peneliti untuk menggali pandangan mereka.

Berdasarkan uraian di atas, maka tulisan hanya akan mengkaji tentang pandangan Hizbut Tahrir (HT) terhadap cara penegakan daulah khilafah Islam yang dilakukan oleh ISIS pimpinan Abu Bakar al-Baghdadi. Hal tersebut sangat menarik untuk dikaji, agar dapat berkonstribusi bagi masyarakat Islam pada umum yang kadang masih menyamakan dakwah penegakan daulah khilafah Islam yang dilakukan Hizbut Tahrir dan ISIS. Dengan demikian, tulisan ini diharapkan dapat menjawab kerancuan pandangan masyarakat terhadap kedua gerakan radikal Islam tersebut yang dari awal memang tidak sama.

\section{B. Pembahasan}

\section{Sekilas Gerakan Radikal HT dan ISIS}

Kata "radikal" memiliki sebutan lain yang cenderung anarkis di antaranya: fundamentalis, ekstrim, dan militan. ${ }^{6}$ Keempat istilah

${ }^{5}$ H.M. Ismail Yusanto, "Berkah dan Ancaman" Al-Wa'ie No. 169 Tahun XIX, 1-30 September 2014, hlm. 19

${ }^{6}$ Mohammad Kosim, "Pesantren dan wacana Radikalisme", Karsa, Vol. IX, No. 1, April 2006, hlm. 844. 
tersebut pada umumnya diarahkan pada individu atau sekelompok orang yang memiliki sikap eksklusif, merasa pandangannya paling benar sendiri, sehingga mereka melakukan kekerasan, baik secara mental maupun fisik. Kata "radikal" ditambah "isme” yakni "radikalisme", bisa diartikan paham yang menginginkan perubahan dengan cara keras atau drastis. ${ }^{7}$ Kelompok Islam radikal kebanyakan berfikiran sempit dan kaku dalam memahami ajaran agama Islam, serta bersifat tertutup dalam memandang ajaran-ajaran kelompok lainnya.

Perkembangan radikalime di Indonesia merupakan suatu kenyataan sosio-historis yang pada akhirnya juga bisa mengancam masa depan pluralisme yang telah terbangun. ${ }^{8}$ Sebab dalam perkembangan lebih lanjut, gerakan radikal ini akan menjadi gerakan militer bersenjata yang sangat membahayakan persatuan dan kesatuan bangsa. Dalam studi ini, akan dibahas dua gerakan Islam yang dipandang radikal dan memiliki cita-cita sama dalam menegakkan daulah khilafah Islam sebagaimana berikut:

\section{a. Hizbut Tahrir (HT)}

Hizbut Tahrir (HT) didirikan pada 1953 oleh Taqi al-Din al-Nabhani di Jerusalem. Al-Nabhani memiliki nama lengkap Muhammad Taqi al-Din ibn Ibrahim ibn Mustafa ibn Ismail ibn Yusuf al-Nabhani. Nama belakangnya, al-Nabhani, dinisbahkan kepada kabilah Bani Nabhan, yang termasuk orang Arab penghuni padang sahara di Palestina. Mereka bermukim di Ijzim yang termasuk wilayah Haifa di Palestina Utara. Al-Nabhani dilahirkan di daerah Ijzim pada tahun 1909. Ia wafat pada tahun 1398/1977 M, dan dikuburkan di al-Auza'i, Beirut. ${ }^{9}$ Bermula dari Palestina itulah, Hizbut Tahrir (HT) berkembang ke berbagai negara salah satunya Indonesia.

${ }^{7}$ Departemen Pendidikan dan Kebudayaan RI., Kamus Besar Bahasa Indonesia (Jakarta: Balai Pustaka, 1989), hlm. 719.

8 Muhammad Harfin Zuhdi, "Fundamentalisme dan Upaya Deradikalisasi Pemahaman Al-Qur'an dan Al-Hadist", Religia, Vol. 13, No. 1, April 2010, hlm. 89.

9 Syamsul Arifin, Ideologi dan Praksis Gerakan Sosial Kaum Fundamentalis: Pengalaman Hiz̧b al-Tabrir Indonesia (Malang: UMM Press, 2010), hlm. 73. 
Syamsul Arifin mengutip pendapat Solahuddin yang menjelaskan bahwa Hizbut Tahrir masuk ke Indonesia antara 1982-1983. ${ }^{10}$ Kehadiran Hizbut Tahrir ke Indonesia tidak bisa dilepaskan dari tokoh yang bernama Mama Abdullah Nuh, pengelola Pesantren al-Ghazali, Bogor, yang juga dosen Fakultas Sastra Universitas Indonesia. Pada saat itu ia mengundang Abdurrahman al-Baghdadi, seorang aktivis Hizbut Tahrir yang tinggal di Australia, datang ke Bogor membantu pesantrennya. Al-Baghdadi inilah yang kemudian yang kemudian menyebarluaskan gagasan Hizbut Tahrir melalui interaksi dengan para aktivis Islam di Masjid al-Ghifari, Institut Pertanian Bogor (IPB). ${ }^{11}$ Maka, berawal dari Bogor inilah gerakan Hizbut Tahrir (HT) menyebar sampai pelosok Nusantara. Dan kelompok radikal HT tersebut berkembang pesat setelah rezim Orde Baru tumbang.

Institusi kepartaian Hizbut Tahrir yang didirikan alNabhani pada tahun 1953 merupakan basis perjuangan Hizbut Tahrir untuk mendirikan kembali daulah khilafah Islam. Peristiwa sejarah dalam Islam yang dipandang Hizbut Tahrir sebagai momentum kehancuran daulah khilafah Islam adalah setelah kekuasaan Abdul Madjid II berakhir. ${ }^{12}$ Yakni penguasa ke-38 pada zaman kekuasaan Turki Ustmani. Mengenai hal ini, Sharif Zayed Kepala Kantor Media Hizbut Tahrir wilayah Mesir pernah menyatakan bahwa keruntuhan khilafah pada tahun 1924 masehi berada di tangan Mustafa Kemal. Menurutnya, sejak itulah umat Islam kehilangan seorang gembala yang peduli bagi urusan mereka, yang melindungi Islam dan membela kaum muslim. ${ }^{13}$

Berdasarkan peristiwa tersebut, Hizbut Tahrir (HT) oleh al-Nabhani dimaksudkan sebagai basis politik untuk memperjuangkan umat Islam agar bisa bebas dari kemunduran dan penderitaan yang telah berlangsung dalam waktu yang sangat panjang. ${ }^{14}$ Hizbut Tahrir (HT) memandang bahwa upaya untuk

${ }^{10}$ Syamsul Arifin, Studi Islam Kontemporer, hlm. 140.

${ }^{11}$ Ibid., hlm. 140.

${ }^{12}$ Ibid., hlm. 141.

13 Sharif Zayed, "Hizbut Tahrir adalah Gerakan Islam yang Bekerja Membangun Khilafah”, dalam http:/ / hizbut-tahrir.or.id, diakses 03 April 2015.

${ }^{14}$ Syamsul Arifin, Ideologi dan Praksis, hlm. 78. 
membebaskan umat Islam dari kemunduran dan penderitaan adalah jika syariat Islam bisa diterapkan secara menyeluruh. Hizbut Tahrir juga memandang bahwa yang bisa menjamin penerapan syariat Islam adalah daulah khilafah Islam. ${ }^{15}$ Maka berawal dari itulah, dalam beberapa Bulletin Dakwah Al-Islam yang dikeluarkan Hizbut Tahrir, sering temukan seruan untuk menegakkan daulah khilafah Islam.

\section{b. ISIS (Islamic State of Iraq and Syria)}

ISIS singkatan dari Islamic State of Iraq and Syria merupakan kelompok radikal yang memiliki cita-cita mendirikan sebuah negara yang berlandaskan syariat Islam. Ada yang memandang bahwa kelompok ini pada awalnya merupakan binaan maupun ciptaan alQaeda untuk wilayah Irak. Namun, kelompok ini akhirnya meluas di Suriah (Syria) manakala terjadi konflik di wilayah tersebut. ${ }^{16}$ Hal tersebut signifikan dengan ungkapan Arifin yang mengutip pendapat Can Acun yang menyatakan bahwa ISIS merupakan organisasi Islam radikal baru yang merupakan metamorfosis dari al-Qaeda. Sebagaimana al-Qaeda, ISIS juga ingin melaksanakan jihad dalam pengertian sebagai perang melawan kekuatan antiIslam yang pada akhirnya negara Islam (daulah khiläfah Islämiyah) bisa didirikan. Karena secara ideologi tidak berbeda dengan alQaeeda, maka ISIS disebut sebagai Neo-al Qaeda. ${ }^{17}$

Kelompok Islam radikal ISIS didirikan pada tahun 2010 oleh Abu Bakar al-Baghdadi. ${ }^{18}$ Berawal dari tahun tersebut, ISIS kemudian dikabarkan masuk ke Indonesia sekitar bulan Juli 2014, dengan adanya beberapa kelompok yang melakukan aksi baiat di bundaran HI, Jakarta. Namun, lanjut Aryani yang menyatakan bahwa kemunculan tersebut baru di ketahui oleh khalayak manakala Abu Muhammad al-Indonesiyi, seorang tokoh

${ }^{15}$ Ibid., hlm. 78 .

16 Yanuana Ahmad Samantho, Sejarah ISIS dan Illuminati Jakarta: Ufuk Publishing House, 2014), hlm. 29.

${ }^{17}$ Syamsul Arifin, Studi Islam Kontemporer, hlm. 60.

${ }^{18}$ Devi Aryani, "Fenomena Radikalisasi Gerakan ISIS di Indonesia: Analisis Isi terhadap Berita pada Media Online mengenai Gerakan ISIS di Indonesia”, Skripsi (Surakarta: UMS, 2015), hlm. 4. 
ISIS Indonesia tampil berapi-api pada tanggal 8 Agustus 2014 di Youtube berjudul "Join The Ranks", artinya ayo bergabunglah!. Dalam Youtube tersebut Abu Muhammad al-Indonesiyi mengajak seluruh umat Islam bergabung dengan kelompok tersebut. Berbeda dengan hal di atas, ada pendapat yang menyebutkan bahwa ISIS mendeklarasikan berdirinya daulah khilafah Islam pada tanggal 29 Juni 2014 di Irak dan Suriah (Syria).

Pasca tampilnya Abu Muhammad al-Indonesiyi di Youtube tersebut menjadi awal adanya kelompok Islam radikal baru dengan nama ISIS di negara Indonesia. Tentu saja, kelompok Islam radikal ISIS yang dipandang banyak melakukan tindakan yang tidak manusiawi, melakukan kekerasan, pembunuhan, perampokan, dan semacamnya tersebut banyak mendapat kecaman dari umat Islam Indonesia yang mayoritas bisa bersikap moderat dan toleran. Tak hanya berhenti di situ, ternyata kelompok ISIS juga mendapat kecaman dari kelompok-kelompok Islam radikal yang telah lebih dulu tumbuh di Indonesia, salah satunya adalah Hizbut Tahrir (HT). Kelompok Islam radikal Hizbut Tahrir (HT) mengutuk keras atas tindakan tidak manusiawi yang dilakukan oleh ISIS.

\section{Dasar Penegakan Daulah Khilafah Islam}

Sebenarnya, dasar dari kedua kelompok radikal (HT dan ISIS) dalam mewujudkan cita-cita menegakkan daulah khilafah Islam tersebut diambil dari sumber hukum yang sama, yakni al-Qur'an dan al-Hadist. Akan tetapi, cara atau gerakan yang mereka lakukan dalam mewujudkan cita-cita tersebut memang berbeda. Bagi Hizbut Tahrir, menegakkan daulah khilafah Islam merupakan kewajiban bagi seluruh umat Islam, dan bukan hanya kewajiban Hizbut Tahrir (H'T) saja. Dalam buku berjudul "Struktur Negara Khilafah: Pemerintahan dan Administrasi" disebutkan bahwa sistem pemerintahan yang diwajibkan oleh Tuhan penguasa alam semesta adalah sistem khilafah. Di dalam sistem khilafah tersebut, khalifah (imam/pemimpin) diangkat melalui bait berdasarkan Kitabullah dan Sunnah Rasul-Nya untuk memerintah sesuai dengan wahyu yang Allah turunkan. ${ }^{19}$

${ }^{19}$ Hizbut Tahrir, Struktur Negara Khilafab: Pemerintahan dan Administrasi (Jakarta: HTI Press, 2008), hlm. 14. 
Pandangan Hizbut Tahrir Terhadap Radikalisme Gerakan Isis....

Dalil-dalil al-Qur'an yang dijadikan justifikasi dalam mendirikan daulah khilafah Islam oleh Hizbut Tahrir adalah: "Wahai orang-orang yang beriman taatilah Allah dan taatilab rasul-Nya, dan ulil amri di antara kamu" ${ }^{20}$ Kata "ülil amr" dalam ayat tersebut menurut Hizbut Tahrir adalah mentaati para imam/khalifah. Perintah untuk mentaati ulil amri ini adalah dalil wajibnya mengangkat ulil amri, sebab tak mungkin Allah memerintahkan umat Islam untuk mentaati sesuatu yang tidak ada. Dengan kata lain, perintah mentaati ulil amri ini berarti perintah mengangkat ulil amri. Jadi ayat tersebut menunjukkan bahwa mengangkat seorang imam (khalifah) bagi umat Islam adalah wajib hukumnya. ${ }^{21}$

Ayat lain yang dipakai dalil wajibnya menegakkan daulah khilafah Islam adalah: "Dan putuskanlah perkara mereka menurut apa yang diturunkan Allah dan janganlah kamu mengikuti hawa nafsu mereka dengan meninggalkan kebenaran yang telah datang kepadamu"22 Bagi Hizbut Tahrir (HT), ayat ini menunjukkan bahwa Allah telah memerintahkan Rasulullah saw untuk memberikan keputusan hukum di antara kaum muslimin dengan apa yang diturunkan Allah (syariat Islam). Ayat tersebut, bahkan semua ayat yang memerintahkan berhukum pada hukum Allah merupakan dalil yang menunjukkan wajibnya mengangkat seorang imam (khalifah) yang akan menegakkan syariat Islam.

Selain itu, Hizbut Tahrir juga merujuk hadist-hadis Rasulullah saw sebagai dasar penegakan daulah khilafah Islam sebagaimana berikut: "Siapa saja yang melepaskan tangan dari ketaatan (kepada khalifah), niscaya ia akan menemui Allah kelak pada hari kiamat tanpa memiliki bujjah. Siapa saja yang mati, sementara tidak ada baiat (kepada khalifah) dipundaknya, maka ia mati seperti kematian jahiliyah"23 Dalam riwayat Thabrani disebutkan bahwa Nabi Muhammad saw bersabda: "Siapa yang mati, sementara tidak. ada imam atasnya, maka ia mati seperti kematian jabiliyah" 24 Hadist

\footnotetext{
${ }^{20}$ Q.S. an-Nisa' [4]: 59.

${ }^{21}$ Abdullah Umar Sulaiman ad-Dumaiji, Al-Imāmah Al-'Udžmā Inda Abli alSunnah wa Al-Jamä'ah ((Kairo: t.p., t.t.), hlm. 49.

${ }^{22}$ Q.S. al-Ma’idah [5]: 48.

${ }^{23}$ H.R. Muslim.

${ }^{24}$ H.R. Thabrani.
} 
riwayat Imam Ahmad dari Muawiyah yang berbunyi: "Siapa saja yang mati tanpa imam (khalifah), ia mati seperti kematian jabiliyah." 25

Hizbut Tahrir memandang bahwa sabda Nabi saw "ia mati seperti kematian jahiliyah" (mäta mìtatan jähiliyyatan) di atas, sesuai dengan ketentuan ushul, merupakan qarinah (indikator) yang tegas sehingga perintah menegakkan daulah khilafah dan berbaiat kepada khalifah/imam adalah sebuah kewajiban umat Islam. ${ }^{26}$ Dalam hal tersebut, Rudianto menyatakan: "Saat ini belum ada imam/khalifah sehingga belum ada baiat di atas tengkuk. setiap muslim. Karena itu, untuk menyelamatkan diri dari kematian jabiliyah itu, setiap muslim wajib berusaba serius untuk mewujudkan adanya khalifah itu, yakni dengan menegakekan khilafah, tentu melalui dakwah secara berjamaah menggunakan metode yang telah digariskan dan dijelaskan Rasul saw dalam sirah beliau'. Pernyataan inilah nanti yang membedakan cara yang ditempuh HT dengan ISIS dalam mewujudkan cita-cita menegakkan daulah khilafah Islam.

Selain dalil di atas, al-Murtadha, seorang Dewan Pimpinan Pusat Hizbut Tahrir Indonesia (HTI) juga menyusun sebuah kitab yang berjudul Aqwäl al-Ulamā 'an Wujüb al-Khiläfah sebagai pegangan Hizbut Tahrir (HT) yang menjelaskan tentang perkataan-perkataan para ulama terkemuka mengenai wajibnya imamah dan khilafah. Al-Murtadha menegaskan pula dalam kitab tersebut merupakan hasil istimbath para ulama dari dalildalil syara'. Bisa disebutkan disini para ulama yang dimaksud diantaranya; Abu Zakariya bin Yahya bin Syaraf an-Nawawi, Syaikh Muhammad as-Syarbini, Syaikh Abdul Hamid as-Syarwani, dan lain sebagainya. ${ }^{27}$

\section{Empat Pilar Daulah Khilafah Islam}

Dalam studi ini perlu disebutkan pula mengenai "Empat Pilar Daulah Khilafah Islam” dalam konsep Hizbut Tahrir (HT). Penyebutan tersebut akan digunakan untuk mengkaji pandangan

${ }^{25}$ H.R. Ahmad.

${ }^{26}$ Yoyok Rudianto, "Kewajiban Menegakkan Khilafah" dalam Al-Wa'ie, No. 169, Tahun XIV, 1-30 September 2014, hlm. 61.

${ }^{27}$ Lihat lebih jelas Mustafa Ali al-Murtadha, Aqwāl al-'Ulamā 'an Wujūb alKhiläfah (t.a: Dar as-Salam, 1433 H), hlm. 3-7. 
Hizbut Tahrir (HT) terhadap cara penegakan daulah khilafah Islam yang dilakukan ISIS. Sehingga dengan demikian, akan tampak perbedaan dari kedua gerakan radikal tersebut. Kiai Haji M. Shiddiq al-Jawi, selaku Dewan Pimpinan Pusat Hizbut Tahrir dalam Seminar Khilafah Islamiyah bertema "Khilafah Solusi Terbaik Permasalahan Umat" yang diadakan di Gedung Teater Tertutup Taman Budaya Bengkulu, Minggu 10 Juni 2012 telah menjelaskan empat pilar negara khilafah (daulab khiläfah) yaitu:

\section{a. Kedaulatan di tangan syariah (al-siyādah li al- syar'i)}

Artinya yang berhak mengatur manusia hanyalah syariah Islam, bukan hukum yang lain. Sebab definisi kedaulatan (alsiyädah) adalah otoritas tertinggi yang bersifat mutlak yang merupakan satu-satunya pihak yang berhak mengeluarkan hukum untuk mengatur manusia dan benda-benda yang digunakan manusia. Maka tak ada perbedaan pendapat bagi kalangan ulama dan seluruh umat Islam, bahwa kedaulatan di tangan syariah itu artinya hanya Allah yang berhak menetapkan hukum bagi manusia. Maka bila pilar pertama tentang kedaulatan ini hilang, yakni kedaulatan berubah menjadi di tangan rakyat. Berarti khilafah itu dengan sendirinya sudah hancur dan berubah menjadi sistem demokrasi. Dalam demokrasi, kedaulatan di tangan rakyat, yang berarti bahwa satu-satunya pihak yang berhak mengatur hidup manusia adalah manusia itu sendiri, bukan Allah swt. Inilah perbedaan paling mendasar antara sistem khilafah dengan sistem demokrasi. Dalam khilafah, kedaulatan di tangan syariah. Sedang dalam demokrasi, kedaulatan di tangan rakyat.

\section{b. Menetapkan kekuasaan di tangan umat (al-sulthān li al-ummah)}

Kekuasaan (al-sulthān) didefinisikan sebagai otoritas untuk menetapkan hukum-hukum dan perundang-undangan. Pilar kekuasaan di tangan umat (al-sulthān li al-ummah) ini mengandung arti bahwa umatlah yang berhak memilih pemimpin yang dikehendakinya untuk menjalankan kekuasaan. Hal ini dapat dipahami dari hadist-hadist tentang baiat, bahwa seseorang tak 
menjadi pemimpin (khalifah), kecuali dibaiat (dipilih) oleh umat. Juga dapat dipahami dari hadist tentang pengangkatan pemimpin (ta'mir), yakni bahwa dalam perjalanan oleh tiga orang, harus diangkat pemimpin (amir) oleh pihak yang dipimpin (yakni umat). Maka bila pilar tentang kekuasaan ini hilang, yaitu kekuasaan tak lagi di tangan umat, misalnya berubah menjadi di tangan keluarga atau suku tertentu, berarti khilafah itu sudah hancur dan berubah menjadi sistem monarki (kerajaan). Contoh monarki adalah Kerajaan Saudi Arabia yang kekuasaannya berada di tangan keluarga Ibnu Saud secara eksklusif. Inilah perbedaan mendasar khilafah dengan sistem monarki. Dalam khilafah, kekuasaan di tangan umat. Sedangkan dalam sistem monarki, kekuasaan secara eksklusif dimiliki oleh keluarga tertentu.

\section{c. Mengangkat satu orang khilafah adalah wajib atas seluruh kaum muslimin}

Pilar ini mempunyai dua dimensi pengertian, yaitu: (1) khalifah yang diangkat wajib satu orang saja, tidak boleh lebih; (2) mengangkat khalifah itu sendiri adalah wajib hukumnya, bukan sunnah, mubah, dan sebagainya. Maka bila pilar ketiga ini hilang dalam negara khilafah, misalnya khalifah yang diangkat ada dua orang, maka otomatis khilafah telah hancur dan berubah menjadi sistem lain. Sebab syariah Islam telah mengharamkan membaiat dua orang khalifah pada waktu yang sama. Jadi, pilar ketiga ini memastikan persatuan umat di bawah satu kepemimpinan. Maka dari itu, jelas keliru sekali kondisi umat Islam yang terpecah belah dipimpin oleh banyak pemimpin sebagaimana dalam sistem negara-bangsa (nation state) sekarang ini. Demikian pula juga suatu kekeliruan jika mengangkat khalifah tidak lagi dianggap sebagai kewajiban, atau malah dianggap perbuatan kriminal.

\section{d. Khalifah mempunyai hak khusus dalam melegislasikan hukum syara' menjadi UUD dan segenap UU}

Hal ini didasarkan pada ijma shahabat yang melahirkan kaidah syar'iyah yang termasyhur, "amru al-imam yarfa'u alkhiläf' (perintah imam atau khalifah menghilangkan perbedaan pendapat). Juga kaidah syar'iyah lain yang tak kalah masyhur, 
"li al-imam an yubditsu min al-aqdhiyāti bi qadri mā yahdutsu min almusykiläe' (imam atau khalifah berhak menetapkan keputusan baru sejalan dengan persoalan-persoalan baru yang terjadi). Maka bila pilar keempat ini tidak ada, misalnya hak legislasi diserahkan kepada lembaga legislatif, bukan menjadi hak khusus khalifah, maka khilafah hakikatnya sudah hancur dan berubah menjadi sitem demokrasi yang menetapkan hak legislasi ada di tangan lembaga legislatif. ${ }^{28}$

\section{Pandangan HT terhadap Daulah Khilafah ISIS}

Ali Mustofa Akbar, seorang tokoh Hizbut Tahrir (HT) menyatakan bahwa ISIS adalah permainan kaum sekuler-liberal (baca; Barat), dan hanya dimanfaatkan untuk menjatuhkan Islam terutama dalam hal "khiläfah Islämiyah" serta memiliki tujuan, antara lain: (a) untuk memberikan citra negatif pada khilafah. Isu ISIS digunakan oleh pihak-pihak tertentu untuk memberikan stigma negatif kepada gagasan khilafah. Isu ini selalu dilekatkan dengan topik pembahasan seputar negara Islam dan khilafah. Sistem khalifah yang begitu mulia digambarkan oleh mereka sebagai sebuah sistem yang kejam, menakutkan, diskriminatif, sumber konflik, dan seterusnya; (b) kriminalisasi terhadap perjuangan mulia menegakkan khilafah. Selain menggiring isu ISIS untuk memberikan citra negatif terhadap khilafah, topik ini juga diseret untuk mengkriminalisasi perjuangan penegakan ideologi Islam. Mereka menggeneralisasi bahwa pihak-pihak yang memperjuangkan khalifah adalah sama bahayanya dengan ISIS; (c) mensekulerkan umat Islam. Setelah mencitrakan khilafah dengan sedemikian buruk, kaum sekuler-liberal berupaya menampilkan sekaligus mengkampanyekan Islam sekuler (Islam yang memisahkan agama dengan kehidupan). Bagi mereka Islam cukup aktivitas ritual dan spiritual belaka tanpa adanya formalisasi syariat. Menurut mereka, syariat dan khilafah tidak wajib diterapkan, gagasan utopis, tidan relevan, dan seterusnya. ${ }^{29}$

${ }^{28}$ Lihat lebih lengkap KH. M. Shiddiq Al-Jawi, "Empat Pilar Negara Khilafah" dalam http:/ / hizbut-tahrir.or.id, diakses 03 April 2015.

${ }^{29}$ Lebih lengkap Ali Mustofa Akbar, "Monsterisasi Khilafah (Dibalik BlowUp ISIS di Indonesia“), Al-Wa’ie, No. 169, Tahun XIX, 1-30 September 2014, hlm. 54-56 
Walau gerakan HT dan ISIS memiliki cita-cita yang sama, namun Hizbut Tahrir (HT) menolak cara penegakan daulah khilafah Islam yang dilakukan ISIS dan menganggapnya tidak absah. Hal tersebut signifikan dengan pernyataan yang disampaikan Ismail Yusanto, selaku Jubir Hizbut Tahrir Indonesia (HTI) berikut: "Sikap Hiøbut Tabrir sendiri dalam soal ini sangatlah jelas, sebagaimana termuat di situs Hiðbut Tabrir Indonesia (HTI). Intinya, Hizbut Tabrir menolak keabsahan kekhalifahan yang dideklarasikan oleh ISIS yang dipimpin Abu Bakar al-Baghdadi. Pasalnya, khilafah ala ISIS tidak memenuhi empat syarat sekaligus". ${ }^{30}$ Dengan demikian, Hizbut Tahrir (HT) memandang bahwa empat syarat tersebut merupakan kunci utama dalam mendirikan daulah khilafah Islam.

Empat syarat yang tidak dipenuhi ISIS sebagaimana dijelaskan Yusanto antara lain: (a) khilafah semestinya menguasai satu wilayah otonom, bukan berada di bawah sebuah negara. Kenyataannya khilafah ala ISIS sebagian di Irak dan sebagian di Suriah. Secara faktual khilafah itu tidak memiliki kekuasaan yang nyata (sulthān dzäatiyan); (b) semestinya khilafah mengontrol penuh keamanan dan rasa aman di wilayah itu. Kenyataannya, karena wilayah kekhalifahan ala ISIS di dalam Irak dan Suriah, tentu keamanan wilayah itu sebagian berada di tangan pemerintahan Irak dan sebagian lagi ada di Suriah; (c) khilafah semestinya mampu menerapkan syariah Islam secara adil dan menyeluruh (käffah). Kenyataannya, hingga sekarang tidak jelas khilafah apa yang dimaksud ISIS, bagaimana sistem politik pemerintahannya, bagaimana sistem ekonominya dan sebagainya; (d) pengangkatan khalifah semestinya memenuhi seluruh syarat-syarat pengangkatan (syuruth al-in'iqäds), yaitu muslim, laki-laki, balig, berakal, merdeka, adil dan mampu, serta dibaiat dengan prinsip ridhā wal ikhtiyār (kerelaan dan pilihan) oleh umat Islam di wilayah itu setelah opini tentang khilafah berkembang dan menjadi kesadaran umum di tengah masyarakat. Kenyataannya, ia hanya dibaiat oleh para milisi pengikutnya saja. ${ }^{31}$

Hizbut Tahrir (HT) melalui jurbirnya, Ismail Yusanto menyampaikan sebagaiamana bahwa metode perjuangan

${ }^{30}$ H.M. Ismail Yusanto, "Berkah”, hlm. 19

${ }^{31}$ Ibid., hlm. 19-20. 
yang digunakan kelompok radikal ISIS tidaklah sesuai dengan metode Rasulullah saw dalam mendirikan negara (daulah). Sebab Rasulullah saw dalam menegakkan daulah khilafah Islam tidak pernah menempuh jalan kekerasan, apalagi menghancurkan tempat ibadah, melakukan pembunuhan dan sebagainya. ${ }^{32}$ Bahkan dalam hal tersebut, Yusanto juga mengingatkan bahwa khilafah adalah negara yang punya bobot. Dengan demikian, tentu saja proklamasinya akan menjadi peristwa yang hebat dan mengguncang dunia dan bukan seperti deklarasi ISIS yang justru menjadi cemoohan di mana-mana. ${ }^{33}$ Dengan demikian, Hizbut Tahrir (HT) memandang bahwa segala kekerasan yang dilakukan ISIS dalam mewujudkan daulah khilafah Islam tidak sesuai dengan cara yang ditempuh Rasulullah saw.

Bahkan Yusanto menyatakan bahwa umat Islam harus waspada agar isu ISIS tidak dijadikan alat untuk menjauhkan Islam dari umatnya. Umat Islam harus membedakan tindak kekerasan ISIS dengan khilafah sebagai gagasan yang berasal dari Islam. ${ }^{34}$ Berdasarkan pernyataan Yusanto tersebut, maka ada perbedaan yang benar-benar harus diperhatikan antara "tindak kekerasan ISIS" dengan "khilafah sebagai ide dari Islam". Dalam hal ini, Hafidz Abdurrahman selaku Ketua Lajnah Tsaqafiyah DPP Hizbut Tahrir Indonesia menyatakan bahwa khilafah alà minhäj al-nubuwwah menerapkan Islam secara sempurna, dengan baik dan benar, jauh dari sifat barbarian, apalagi berlumuran darah, baik darah kaum minoritas non-muslim maupun kaum muslim yang berbeda paham dengannya. ${ }^{35}$ Tentu tindak kekerasan ISIS yang mengklaim dirinya menegakkan daulah khilafah Islam tersebut tidak sesuai dengan minhäj al-nubumwah.

Hizbut Tahrir (HT) memandang bahwa kelompok radikal ISIS merupakan gerakan yang zalim dan telah melakukan pendistorsian terhadap gagasan khiläfah alà minhäj al-nubuwwah. Bukti bahwa kelompok radikal ISIS merupakan gerakan yang

${ }^{32}$ H.M. Ismail Yusanto, "Berkah" hlm. 20

${ }^{33}$ Ibid., hlm. 20

${ }^{34}$ Ibid., hlm. 21

${ }^{35}$ KH. Hafidz Abdurrahman, "Benarkah Khilafah Berlumuran Darah", AlWa’ie, No. 169, Tahun XIX, 1-30 September 2014, hlm. 43 
zalim, di antaranya; ISIS telah membunuh Abu Bakar Mustafa Khayal, seorang laki-laki anggota Hizbut Tahrir yang bersih dan takwa. Pembunuhan tersebut dilakukan kelompok radikal ISIS kepada Abu Bakar Mustafa Khayal bukan karena sesuatu hal yang signifikan, melainkan karena Khayal mengatakan kalimat al-haq, agar kelompok radikal ISIS menanggalkan kejahatan-kejahatan mereka terhadap kaum muslimin. ${ }^{36}$

Hizbut Tahrir (HT) juga menunjukkan bukti lain bahwa kelompok radikal ISIS telah membunuh jiwa-jiwa yang suci, melanggar kehormatan-kehormatan, sampai berbagai kejahatankejahatan mereka melampaui manusia dan menimpa pepohonan dan bebatuan. Abu Bakar Mustafa Khayal menyatakan: "Kami juga menyampaikan kepada mereka (ISIS) peringatan-peringatan atas akibatakibat dari berbagai kejahatan tersebut yang mewariskan kehinaan di dunia dan azab pedih di akhirat...". 37 Berdasarkan hal tersebut, Hizbut Tahrir (HT) memandang bahwa penegakan daulah khilafah Islam yang dilakukan kelompok radikal ISIS tidak sesuai dengan tuntunan Rasulullah saw.

Sharif Zayed, selaku Kepala Kantor Media Hizbut Tahrir wilayah Mesir menyatakan bahwa Hizbut Tahrir tidak melakukan tindakan fisik dan tidak menganut cara kekerasan sebagai cara untuk mendirikan khilafah, karena Nabi saw menolak untuk melakukannya. Hizbut Tahrir terjaga siang dan malam untuk interaksi dengan umat dan untuk memahamkan Islam sebagai jalan hidup, dan bahwa kewajiban ini harus diterapkan di negara khilafah, sebagaimana yang dilakukan Nabi saw, sehingga kewajiban khilafah mendapatkan kesadaran publik dan menjadi tuntutan massa yang tidak lagi puas dengan sistem pengganti lain". ${ }^{8}$ Dengan demikian, cara yang dilakukan kelompok ISIS dalam menegakkan daulah khilafah Islam sangat bertentangan dengan cara yang dilakukan Hizbut Tahrir (HT).

${ }^{36}$ Lebih jelas lihat Hizbut Tahrir, "Sampaikan Kalimat al-Haq: Anggota Hizbut Tahrir Suriah dibunuh ISIS", Tabloid Media Ummat, Edisi 140, 12-25 Shafar 1436 H/ 5-18 Desember 2014, hlm. 28

${ }^{37}$ Ibid., hlm. 28

${ }^{38}$ Sharif Zayed, "Hizbut Tahrir", diakses 03 April 2015. 
Pandangan Hizbut Tahrir Terhadap Radikalisme Gerakan Isis....

Bila Hizbut Tahrir (HT) bukan merupakan gerakan bersenjata, maka gerakan radikal ISIS merupakan gerakan bersenjata. Syaikh Atha Abu Rastha, seorang Amir Hizbut Tahrir (HT) menyatakan bahwa ISIS merupakan gerakan bersenjata, baik sebelum proklamasi dan setelah proklamasi. Karena itu, proklamasi ISIS atas tegaknya daulah khilafah Islam merupakan ucapan yang sia-sia (laghwun), dan tidak layak diperhatikan untuk dibahas, sebab pada realitanya sebab sudah tampak jelas. ${ }^{39}$ Dari pernyataan tersebut sudah sangat jelas bahwa Hizbut Tahrir (HT) memandang bahwa penegakan daulah khilafah Islam yang dilakukan kelompok radikal ISIS adalah sesuatu yang sia-sia dan tidak layak diperhatikan serta tidak perlu diikuti daulah khilafah Islamnya, karena tidak berdasarkan tuntunan al-Qur'an dan alHadist. Hal tersebut signifikan dengan ungkapan Yusanto berikut: "...Kalau orang yang berusaha meraih tujuannya dengan menggunakan kekerasan, sudah sangat jelas bahwa Hizbut Tabrir (HT) dalam salah satu prinsip perjuangannya itu 'la unfiyah' (non kekerasan, non violent) dan ini mengikat seluruh anggotanya." 40 Dengan demikian, Hizbut Tahrir (HT) dalam melakukan perjuangannya tidaklah dengan jalan kekerasan sebagaimana sebagaimana yang dilakukan ISIS.

Bahkan Syaikh Atha Abu Rastha menyatakan sebagai berikut: "Saudara-saudara yang dimuliakan. Sesunggubnya perkara al-khilafah al-Islamiyah amatlah agung dan posisinya sungguh sangat signifikan. Berdirinya tidak hanya akan menjadi sekedar berita yang menjadi bahan ejekan media massa, menyesatkan. Akan tetapi dengan ižin Allah, berdirinya khilafah akan menjadi gempa menggema, yang membalikean neraca internasional dan mengubah wajah dan arah sejarah... Sesunggubnya khilafah akan kembali berupa khilafah rasyidah yang mengikuti manhaj kenabian, sebagaimana yang disampaikan kabar gembiranya oleh Rasul saw. Maka orang-orang yang menegakekanny, mereka seperti orang-orang yang menegakkan khilafah rasyidah pertama, orang-orang yang bertakwa

${ }^{39}$ Lihat lebih lengkap Syaikh Atha Abu Rastha, "Politik: Proklamasi Tegaknya al-Khilafah oleh ISIS", dalam Lembaran Silsilah Jawaban Syaikh Atha Abu Rastha, yang penulis dapatkan dari Ustadz Junaidi, anggota Hizbut Tahrir di Blitar, pada 05 April 2015, hlm. 1-2

${ }^{40}$ Muhammad Ismail Yusanto, "Isu ISIS Dijadikan Kedok", dalam Tabloid Media Umat, Edisi 148, 13-26 Jumadil Akhir 1436 H/3-16 April 2015, hlm. 9 
lagi bersih, mencintai umat dan umat mencintai mereka, mereka mendoakan umat dan umat mendoakan mereka. Umat merasakan kebahagiaan bertemu dengan mereka dan mereka merasakan kebahagiaan bertemu dengan umat. Bukannya keberadaan mereka di tengah umat justru dibenci..."

Hal senada juga disampaikan Hamd Fahmi Thabib dalam buku berjudul Khiläfah Rasyidah: Yang Telah Dijanjikean dan Tantangan-tantangannya bahwa peristiwa yang paling agung dalam sejarah umat manusia sejak Nabi Adam as hingga awal tahun pertama sejak hijrahnya Nabi Muhammad saw ke Madinah, setelah ia diangkat menjadi Rasul adalah peristiwa berdirinya daulah khilafah Islamiyah. Karena peristiwa tersebut merupakan hentakan yang kuat yang gaungnya mengguncang dunia beserta umat manusia yang ada di dalamnya. Berdirinya kembali khilafah rasyidah yang kedua yang telah dijanjikan pasti akan berdiri, juga akan menjadi peristiwa paling agung sejak masa berdirinya daulah khilafah Islamiyah pertama hingga masa nantinya. Dengan berdirinya daulah khilafah Islamiyah kedua tersebut, akan terjadi guncangan dasyat, persis seperti apa yang terjadi saat berdirinya daulah khilafah Islamiyah pertama, karena gaungnya akan meliputi seluruh manusia yang ada di muka bumi. ${ }^{42}$

Berdasarkan pernyataan Syaikh Atha Abu Rastha dan Hamd Fahmi Thabib tersebut, ternyata cukup jelas bahwa penegakan daulah khilafah Islam yang dilakukan kelompok radikal ISIS tidak sesuai dengan syarat-syarat yang ditawarkan Hizbut Tahrir (HT) antara lain; (a) berdirinya daulah khilafah Islam yang dilakukan kelompok radikal ISIS malah menjadi bahan ejekan massa dan menyesatkan; (b2) tegaknya daulah khilafah Islam yang diwujudkan kelompok radikal ISIS tidak mengikuti manhaj kenabian; (c) kelompok ISIS jauh dari ciri-ciri orang yang bertakwa lagi bersih; (d) kelompok ISIS jauh dari sikap mencintai umat dan dicintai umat, mendoakan umat dan didoakan umat. Bahkan kedatangan kelompok radikal ISIS mendirikan daulah khilafah Islam dengan cara kekerasan banyak mendapat kecaman dari umat Islam sendiri, dan juga menimbulkan kebencian bagi umat Islam.

\footnotetext{
${ }^{41}$ Syaikh Atha Abu Rastha, "Politik: Proklamasi Tegaknya", hlm. 3

${ }^{42}$ Hamd Fahmi Thabib, Khilafah Rasyidab: yang Telah Dijanjikan dan Tantangantantangannya, (Jakarta: HTI Press, 2008), hlm. 13.
} 
Berdasarkan uraian di atas, dapat dipahami bahwa kelompok Hizbut Tahrir (HT) tampak lebih lunak dibanding kelompok radikal ISIS dalam mewujudkan cita-cita menegakkan daulah khilafah Islam. Akan tetapi dalam konteks Indonesia, tentu saja cita-cita kedua kelompok radikal tersebut akan mengancam empat pilar kebangsaan berikut: (a) Pancasila: sebab baik HT dan ISIS menyatakan bahwa Pancasila sistem kufur dan dianggap thäghut atau berhala. Tentu saja pandangan semacam ini bisa mengancam Pancasila sebagaiideologinegara; (b) UUD 1945: sebab baik HT dan ISIS memandang bahwa UUD 1945 merupakan buatan manusia, bukan buatan Tuhan. Dengan demikian, UUD 1945 tersebut harus diganti dengan penerapan syariah Islam secara keseluruhan di bawah sistem 'Khiläfah ar-rasyìdah alà minhäj al-nubuwwah'. Tentu saja pandangan semacam ini akan bisa mengancam UUD 1945 yang merupakan kesepakatan bersama; (c) Bhineka Tunggal Ika: sebab baik HT dan ISIS yang ingin mendirikan daulah khilafah Islam tidak sepakat dengan semboyan "bhineka tunggal ika", yang menjadi dasar keragaman bangsa Indonesia. Tentu saja, citacita kedua kelompok tersebut dalam menegakkan daulah khilafah Islam, akan mengancam keragaman yang telah terbangun sejak lama; (d) NKRI: sebab langkah-langkah kedua kelompok tersebut (HT dan ISIS) yang ingin mendirikan daulah khilafah Islam, tentu saja akan mengancam keberadaan NKRI yang telah dibangun para pendiri bangsa tercinta.

\section{Simpulan}

Setelah mengakaji berbagai hal di atas, maka studi ini menyimpulkan beberapa hal penting antara lain: Pertama, Hizbut Tahrir (HT) dan ISIS mempunyai cita-cita yang sama yakni menegakkan daulah khilafah Islam. Akan tetapi, kedua gerakan radikal tersebut memiliki cara yang berbeda dalam mewujudkan cita-citanya. Secara umum, perbedaan tersebut terlihat nyata bahwa bila saja Hizbut Tahrir masih tataran ide-ide (pemikiran) dalam mewujudkan daulah khilafah Islam tersebut. Selain itu, tampak Hizbut Tahrir (HT) masih banyak melakukan penanaman pemikiran agar daulah khilafah Islam berjalan dengan baik, tanpa harus melalui pertumpahan darah. Namun, kelompok radikal 
ISIS dalam mewujudkan daulah khilafah Islam sudah dalam level (tataran) gerakan militer bersenjata, yang mana hal tersebut ditolak oleh Hizbut Tahrir (HT) dengan alasan apapun.

Kedua, Hizbut Tahrir (HT) memandang bahwa penegakan daulah khilafah Islam yang dilakukan kelompok ISIS tidak sesuai dengan tuntunan Rasulullah saw dan merupakan buatan negara Barat. Hizbut Tahrir (HT) memandang bahwa ada empat hal yang tidak dilakukan ISIS dalam menegakkan daulah khilafah Islam yaitu: (1) khilafah semestinya menguasai satu wilayah otonom, bukan berada di bawah sebuah negara; (2) semestinya khilafah mengontrol penuh keamanan dan rasa aman di wilayah tersebut; (3) khilafah semestinya mampu menerapkan syariah Islam secara adil dan menyeluruh (käffah); (4) pengangkatan khalifah semestinya memenuhi seluruh syarat-syarat pengangkatan (syuruth al-in'iqädz). Berdasarkan hal tersebut, Hizbut Tahrir (HT) memandang bahwa umat Islam tidak wajib berbaiat pada daulah khilafah Islam yang dilakukan kelompok ISIS. Menurut Hizbut Tahrir (HT), semestinya proklamasi daulah khilafah Islam akan menjadi peristiwa yang hebat dan mengguncang dunia, bukan seperti yang dilakukan kelompok ISIS.

Ketiga, dalam konteks Indonesia, tentu saja cita-cita kedua kelompok radikal HT dan ISIS yang ingin menegakkan daulah khilafah Islam tersebut akan mengancam empat pilar kebangsaan berikut: (1) Pancasila: sebab baik HT dan ISIS menyatakan bahwa Pancasila sistem kufur dan dianggap thäghut atau berhala; (2) UUD 1945: sebab baik HT dan ISIS memandang bahwa UUD 1945 merupakan buatan manusia, bukan buatan Tuhan dan harus diganti dengan penerapan syariah Islam secara keseluruhan di bawah sistem 'khilfäah al-rasyidah alà minhäj al-nubuwwah'; (3) Bhineka Tunggal Ika: sebab baik HT dan ISIS yang ingin mendirikan daulah khilafah Islam tidak sepakat dengan semboyan "bhineka tunggal ika", yang menjadi dasar keragaman bangsa Indonesia; (4) NKRI: sebab langkah-langkah kedua kelompok tersebut (HT dan ISIS) yang ingin mendirikan daulah khilafah Islam, tentu saja akan mengancam keberadaan NKRI yang telah dibangun para pendiri bangsa tercinta. 


\section{DAFTAR PUSTAKA}

Abdurrahman, KH. Hafidz, "Benarkah Khilafah Berlumuran Darah”, Al-Wa'ie No. 169 Tahun XIX, 1-30 September 2014.

Ad-Dumaiji, Abdullah Umar Sulaiman. Al-Imāmah Al-'Udæ̌mā Inda Abli al-Sunnah wa Al-Jamäah. Kairo, t.p. t.t.

Akbar, Ali Mustofa, "Monsterisasi Khilafah (Di Balik BlowUp ISIS di Indonesia), Al-Wa'ie No. 169 Tahun XIX, 1-30 September 2014.

Al-Nabhani, Syaikh Taqi ad-Din. Muqaddimah al-Dustur an al-Asbāb al-Muj̄̄bah Labu, jilid I. Beirut: Darul Ummah, 2009.

Al-Murtadha, Mustafa Ali. 'Aqwāl al- Ulama an Wujūb al-Khilāfah. t.a: Dar as-Salam, $1433 \mathrm{H}$.

Al-Jawi, KH. M. Shiddiq, "Empat Pilar Negara Khilafah" dalam http:/ / hizbut-tahrir.or.id, diakses 03 April 2015.

Arifin, Syamsul. Ideologi dan Praksis Gerakan Sosial Kaum Fundamentalis: Pengalaman Hizb al-Tahrir Indonesia. Malang: UMM Press, 2010.

Studi Islam Kontemporer Arus Radikalisasi dan Multikulturalisme di Indonesia. Malang: Intrans Publishing, 2015.

Aryani, Devi, "Fenomena Radikalisasi Gerakan ISIS di Indonesia: Analisis Isi terhadap Berita pada Media Online mengenai Gerakan ISIS di Indonesia", Skripsi, Surakarta: UMS, 2015.

Departemen Pendidikan dan Kebudayaan RI., Kamus Besar Bahasa Indonesia. Jakarta: Balai Pustaka, 1989.

Kosim, Mohammad, "Pesantren dan wacana Radikalisme", Karsa, Vol. IX, No. 1, April 2006.

Mudzhar, Mohammad Atho, Fatwa-fatwa Majelis Ulama Indonesia. Jakarta: INIS, 1993. 
Rudianto, Yoyok, "Kewajiban Menegakkan Khilafah" Al-Wa'ie, No. 169 Tahun XIV, 1-30 September 2014.

Samantho, Yanuana Ahmad, Sejarab ISIS dan Illuminati. Jakarta: PT. Ufuk Publishing House, 2014.

Tahrir, Hizbut. Struktur Negara Khilafah: Pemerintahan dan Administrasi. Jakarta: HTI Press, 2008.

"'Sampaikan Kalimat al-Haq: Anggota Hizbut Tahrir Suriad dibunuh ISIS", Tabloid Media Ummat, Edisi 140, 12-25 Shafar 1436 H/ 5-18 Desember 2014.

Rastha, Syaikh Atha, "Politik: Proklamasi Tegaknya al-Khilafah oleh ISIS", dalam Lembaran Silsilah Jawaban Syaikh Atha Abu Rastha, diakses pada 05 April 2015.

Rijal, Syamsul, "Radikalisme Islam Klasik dan Kontemporer: Membanding Khawarij dan Hizbut Tahrir", Al-Fikr, Vol. 14, No. 2, 2010.

Rokhmad, Abu, "Pandangan Kiai tentang Deradikalisasi Paham Islam di Kota Semarang”, Jurnal Analisa, Vol. 21, No. 01, Juni 2014.

Thabib, Hamd Fahmi, Khilafah Rasyidab: Yang Telah Dijanjikan dan Tantangan-tantangannya. Jakarta: HTI Press, 2008.

Yayasan Penyelenggara Penerjemah/Penafsir Al-Qur'an Departemen Agama RI. Al-Qur'an Terjemah Per-Kata. Bandung: Syaamil Al-Qur'an, 2007.

Yusanto, H.M. Ismail, "Berkah dan Ancaman" Al-Wa'ie No. 169 Tahun XIX, 1-30 September 2014.

, "Isu Isis Dijadikan Kedok", Tabloid Media Umat Edisi 148, 13-26 Jumadil Akhir 1436 H/3-16 April 2015.

Zayed, Sharif, "Hizbut Tahrir adalah Gerakan Islam yang Bekerja Membangun Khilafah", dalam http://hiz̧buttahrir.or.id, diakses 03 April 2015.

Zuhdi, Muhammad Harfin, "Fundamentalisme dan Upaya Deradikalisasi Pemahaman Al-Qur'an dan Al-Hadist", Religia, Vol. 13, No. 1, April 2010. 